
\title{
ДОШКОЛЬНОЕ ОБРАЗОВАНИЕ В КИТАЕ И РОССИИ: ИСТОРИЧЕСКИЕ ОСОБЕННОСТИ, ОБЩНОСТЬ И РАЗЛИЧИЯ
}

\section{PRESCHOOL EDUCATION IN CHINA AND RUSSIA: HISTORICAL CHARACTERISTICS, COMMONALITY AND DIFFERENCES}

Li Zhenyu

T. Samsonova

Summary: The article deals with the historical data of the emergence of preschool education in China and Russia. A comparative analysis allows determining similarities and differences in approaches and methods of educating the younger generation in the countries having significant historical features of development in the past and unites it present, in the context of the application of modern pedagogical techniques in the education of children of preschool age.

Keywords: China, Russia, preschool education, pedagogy, education, children, history.

\section{Введение}

Дошкольное образование детей младшего возраста волновало и волнует всё человечество, и уже с давних времен по крупицам складывались основы воспитания в Китае и России, которые в XX веке благодаря мировым процессам глобализации и интеграции преобразовались в систему дошкольного образования, имеющую много общего в педагогической и методической направленности.

\section{Шель статьи}

Провести сравнительный анализ существующих систем дошкольного образования в Китае и России. На этом основании наметить черты общности и различия, существующие в системах современного дошкольного образования двух стран, определить основные педагогические и методические тенденции, направленные на улучшение процесса воспитания дошкольников.

\section{Краткий обзор исслеАований по Аанной проблематике}

Литература по дошкольному воспитанию представляет объёмный корпус, изданный на русском и китайском языках как в России, так и в Китае. В связи с обозначенной темой, мы обратились к изданным в настоящее время научным работам русских и китайских авторов, таких как: В.А. Астапова. История дошкольного образо-
Ли Чжэньюй

Преподаватель, Chifeng University China (Kuтаŭ); аспирант, Российский государственный педагогический университет имени А.И. Герцена 931132369@qq.com

Самсонова Татьяна Петровна

Д.ф.н., к.искусствоведения, профессор, Ленинградский государственный университет имени А.С. Пушкина tat4279@yandex.ru

Аннотация: В статье рассмотрены исторические сведения появления дошкольного образования в Китае и России. Проведен сравнительный анализ, позволяющий определить общие черты и различия в подходах и методах воспитания подрастающего поколения в странах, имеющих существенные исторические особенности развития в прошлом и объединяющие их настоящем, в контексте применения современных педагогических приёмов в воспитании детей младшего дошкольного возраста.

Ключевые слова: Китай, Россия, дошкольное образование, педагогика, воспитание, дети, история.

вания в России// М.: Молодой учёный. 2019. №52; К.Ю. Белая. Организация методической работы с педагогами на этапе введения федерального государственного образовательного стандарта дошкольного образования. Справочник старшего воспитателя. М.: Сфера.2014. № 3; С.С. Белоусова. Современное дошкольное образование в Китайской Народной Республике // Новый подход в развитии инноваций в России: сборник материалов международной науч.-практ. конф. (г. Краснодар, 27 января 2018 г.); В.И. Ядешко, Ф.А. Сохина, Т.А. Ильина. Дошкольная педагогика.М.:1986. Нами изучена научная литература, изданная на китайском языке в Китае, таких авторов: Ван Чуньянь, Мен Щанчин, Цй. «Ли цзин», Чен Сесин, Чжан Лисин, Чжу Ципин. На основании изученной литературы на русском и китайском языках в статье представлен авторский взгляд на систему дошкольного воспитания Китая и России в историческом контексте и в свете современных педагогических и методических установок.

\section{Методология}

В статье используются методы исторического и источниковедческого анализа, методы музыкально-педагогических сравнительных характеристик, привлекаются нормативные документы, используются методики дошкольного обучения китайских и российских авторов.

История развития образования Китая, уходящая корнями в глубокую древность, явилась одним из родона- 
чальников мировой системы образования подрастающего поколения, показала важность и необходимость воспитательного процесса с рождения ребенка и до вступления его в полноценную жизнь. Исторические летописи говорят о том, что еще в 2700 году до нашей эры появился «Ян»- сад, ставший прообразом учебного заведения, в котором помимо заботы о стариках обучали детей младшего возраста. В период рабовладельческого общества в Китае, уже началось формирование системы образования, в которой разделялось обучение детей в зависимости от возраста на дошкольное и школьное образование. Об этом упоминается в древнем трактате «Ли цзи - Нэй цзэ», где был представлен проект дошкольного образования для детей рабовладельцев [7]. Этот документ является самой ранней записью о дошкольном образовании в истории Китая. Детям китайской знати преподавались основы этикета, литературы, большое внимание уделялось физической подготовке, а в домах императорской семьи преподавалась музыка, пение, танцы.

В период Конфуцианства, после 475 года до н.э., когда общество перешло в систему феодального устройства, педагоги древности считали воспитание детей в самом раннем возрасте важным фактором развития нравственных норм, которые закладывали основу честности, добропорядочности и трудолюбия, уважения к родителям и почитания религии, которая была в те времена основой власти в Китае [6].

На протяжении веков, постепенно складывалась китайская система дошкольного образования, включая все периоды развития государства, как при правлении множественных династий, так и в последующие периоды. В середине XIX века уже появились специальные дошкольные учреждения, а в период Великой китайской революции начали открываться детские сады, не только для знати, но и для детей рабочих и крестьян [8].

B XX веке продолжилось формирование дошкольного образования. С 1903 по 1918 год программа дошкольного образования в Китае в основном имитировала японскую модель. 13 января 1904 года был обнародован первый в Китае закон о дошкольном образовании. Его основное содержание основано на «Правилах по детскому саду и оборудованию для детей», обнародованных Японией в 1899 году.

После движения за новую культуру «4 мая» в 1919 году становятся популярными передовые западные идеи, а ранние китайские дошкольные педагоги, такие как Чэнь Хэцинь, Тао Синчжи, Чжан Сюэмень, Цянь Сюаньтун, Лю Баньнун, Бин Синь и Ху Ши начали выступать против конфуцианских устоев и призывали к созданию новой китайской культуры, основанной на мировых и западных стандартах.

С 1920-х по 1930-е годы реформа учебной программы в детском саду теоретически подтвердила доминирующий статус детей и определила, что учебная программа для детского сада должна быть основана на повседневной жизни детей.

В октябре 1932 года правительство Китайской Республики официально обнародовало первый в истории дошкольного образования стандарт учебных программ - «Стандарты учебных программ для детских садов», которые открыли новую эру в образовательных программах дошкольного образования в Китае и открыли первый важный период в разработке программ дошкольного образования на государственном уровне. В это время сфера охвата дошкольной программы для детского сада была относительно обширной и практичной. Кроме того, систематизация и научность дошкольной программы детского сада всегда была предметом реформ.

В 1950-х годах наиболее заметной чертой реформы дошкольной программы в китайском детском саду было изучение опыта дошкольного образования в Советском Союзе и внедрение моделей обучения и предметных программ (музыкальные занятия, рисование, танцы).

Благодаря помощи Советского Союза в Китае произошли значительные изменения в педагогической науке и практике. Множество советских ученых и педагогов пропагандировали в Китае передовой педагогический и методический опыт. По всей стране при помощи педагогов из страны Советов создавались экспериментальные детские сады, в работе которых использовались разработанные в СССР психолого-педагогические подходы, методические разработки и т.п. [3, с. 37].

Пришедшее в упадок образование в Китае, после культурной революции, начало восстанавливаться лишь в конце 70-х годов XX века [4].

Российская система дошкольного образования не столь древняя как китайская, но путь развития страны за сравнительно короткий период времени, показал, что успехи в области образования в России могут конкурировать с большинством стран мира и во многом превосходят образовательные стандарты Европы и Америки по качеству обучения.

Путь дошкольного образования в России обозначен

1 Движение за новую культуру середины 1910-х и 1920-х годов возникло из-за разочарования в традиционной китайской культуре после неудачи Китайской республики, основанной в 1912 году, для решения проблем Китая. 
на основе исторических летописей, начинается с этапа образования Киевской Руси в IX-XII вв. В тоже время при монастырях и церквях стали появляться и первые учебные заведения (церковно-приходские школы, школы певчих). Создавались первые методики обучения, учитывающие возрастные категории, сословия, материальные и территориальные признаки [1, с. 270].

Первый в России сад для малообеспеченных детей открылся в 1866 году в Санкт-Петербурге. Тогда же Аделаидой Симонович² был организован частный детский сад, в котором проходили обучение дети петербургской знати [2, с. 45]. В 1913 - 1917 гг. вице-президентом СанктПетербургского Общества содействия дошкольному воспитанию была Тихеева Елизавета Ивановна, знаменитый педагог-новатор. Она изучала вопросы дидактики и опробовала методики дошкольного обучения. С 1913 года Тихеева Е.И. взяла на себя руководство детским садом, который был основан Обществом содействия дошкольному воспитанию [11].

Преобразования в России после Великой Октябрьской революции в 1917 году коснулись и образования. Вместо разрозненных казённых, частных школ была создана единая государственная система народного образования. В советский период государственные детские сады проводили подготовку по единому плану и графику, игнорируя развитие личности детей. Впоследствии под влиянием российских педагогов система дошкольного образования претерпела реформирование, и по сей день учебная программа, программное и аппаратное обеспечение, а также методы обучения в российских детских садах отражают уважение индивидуальных различий детей.

Концепции и модели дошкольного образования в Советском Союзе оказали глубокое влияние на дошкольное образование в Китае, а затем Китай и Россия провели различные реформы в своих соответствующих областях дошкольного образования. В результате тесного сотрудничества развитие дошкольного образования в обеих странах обрело свои сильные стороны, но и столкнулось с рядом проблем, которые успешно разрешались благодаря совместной научной деятельности в области педагогики, и разработке новых методов преподавания и подходов к обучению детей с учетом национальной специфики подготовки педагогических кадров.

Педагогический этап дошкольного обучения в России входит в рамки обязательного образования. В России дошкольное образование могут получить дети от двух месяцев до 7 лет. В России в настоящее время дошкольное образование отличается от китайского разделением учебных заведений на детские ясли и детские сады.

Российским законодательством не предусмотрена необходимость обязательного дошкольного образования детей до поступления в общеобразовательные школы, поэтому незначительная часть детей может получать до школы домашнее воспитание. Дошкольные образовательные учреждения в России, как правило, включают обычные государственные детские сады, частные детские сады, специализированные детские сады компенсирующего типа для детей с особенностями развития, сады присмотра и оздоровления, комбинированные детские сады, и центры дошкольного развития, дошкольные классы и классы по интересам на базе средних учебных заведений и другие учреждения воспитательного характера.

В Китае дошкольным образованием пользуются около 90\% городских жителей, в деревнях менее $20 \%$ детей ходит в детский сад. В Китае придерживаются российской модели дошкольного воспитания и возможного воспитания в семье до поступления в среднюю школу, но до родителей доводится, что дети, проходящие обучение в детских садах, имеющих целью не только воспитательный процесс, но и подготовку к школе имеют лучшие показатели по способности к обучению, и восприятию школьного материала в будущем, по сравнению с детьми не посещавших детский сад.

В Китае дети могут ходить в детский сад в возрасте от 3 до 6 лет в городе и до 7 лет в деревне, а зачисление ребенка в государственный или ведомственный детский сад платное. Формы занятий коллективные, направленные на воспитание в ребенке чувства коллективизма, при строгом соблюдении дисциплины. В отличие от российских детских садов в большинстве дошкольных учреждений Китая детей приучают к ношению форменной одежды. Важным моментом в китайском детском саду является патриотическое воспитание: каждое утро начинается с поднятия государственного флага [5].

При поступлении на работу к воспитателям детских садов в Китае предъявляют высокие требования, которые не только должны иметь высшее образование в области дошкольного образования или развития ребенка, но обязательно должны иметь квалификацию учителя. В системе дошкольного образования на данный момент в Китае прописаны необходимые знания для педагогов и методистов детского сада: законодательная база, регла-

2 Аделаида Семёновна Симонович ( 6 апреля 1844, Москва - 9 ноября 1933) - российский педагог, издатель, первый российский теоретик дошкольного обучения.

3 Елизавета Ивановна Тихеева (1867-1943) - российский и советский педагог, крупнейший специалист по дошкольному воспитанию детей, руководитель опытного детского сада при Ленинградском государственном педагогическом институте им. А. И. Герцена. 
мент деятельности детских садов, учитываются запросы «пользователей» образовательных услуг, обеспечивается профессиональная подготовка соответствующих носителей образовательных услуг, уделяется серьезное внимание научно-методическому обеспечению.

На современном этапе каждый педагог детского сада в Китае обязан периодически проходить переподготовку и повышать свою квалификацию; участвовать в педагогических форумах, конференциях и семинарах для педагогов детских садов. Такой процесс постоянной подготовки и переподготовки способствует улучшению качества работы педагогов. Многие воспитатели получают ученые степени, проходя дополнительное обучение в университетах, как в Китае, так и в России. [9, с. 9].

Под контролем государства российское дошкольное образование постоянно реформировалось и совершенствовало свои методы подготовки учителей, а также сформировало систему обучения и подготовки учителей для дошкольных учреждений с высоким уровнем профессиональной подготовки, знанием системы образования и высокой работоспособностью. В России многие педагогические вузы имеют факультеты дошкольного образования, выпускающие дипломированных специалистов высокой квалификации. Подготовка преподавателей дошкольного образования в российских университетах направлена на изучение и овладение общим гуманитарным знанием, профессиональными и техническими методиками в области образования и практическими навыками.

Оценка будущих педагогов дошкольных учреждений в Китае складывается из контроля полученных знаний, личных достижений студентов за время обучения, практической успеваемости и качества применения теоретических знаний во время занятий с детьми, как в группах, так и во время индивидуальных занятий. Оценка практических навыков складывается из результатов «полевого» опыта студентов и стажировки в учебных заведениях дошкольного образования. Основная цель - дать будущим педагогам возможность общаться с детьми, родителями, применять полученные знания, навыки и профессиональные установки, приобретенные в результате обучения и взаимодействия между коллегами в процессе прохождения учебной практики. Стажировка - это последний период подготовки к непосредственной работе в образовательном учреждении после окончания ВУЗа. Стажеры постепенно и независимо входят в фактическую среду обучения под руководством преподавателей. Это процесс, в котором учащиеся всесторонне используют знания и навыки. Оценка «полевого» опыта студентов и результатов стажировки придает большое значение для закрепления полученных теоретических знаний, таких как способность понимать личность и уровень развития детей, а также способность общаться с родителями воспитанников. Большое количество исследований показало, что у молодых учителей возникнет много проблем, когда они входят в реальную педагогическую жизнь, но приобретенные за время учебы знания и умения позволяют быстро адаптироваться к новым реалиям [10].

\section{ОбсужАения и выводы}

Современные образовательные технологии, которые успешно внедряются в российском дошкольном образовании, ещё не «охвачены» китайской дошкольной педагогикой. Это отставание, надо надеяться, будет преодолено в ближайшем будущем. Федеральный Государственный Образовательный Стандарт (ФГОС-2013) ${ }^{4}$ даёт широкий спектр использования инновационных технологий в системе дошкольного образования. Укажем на основные положения инновационных технологий, которые классифицируются следующим образом: 1) по уровню применения-локальные, отраслевые, общепедагогические; 2). по концепции усвоения: развивающие, ассоциативно- рефлекторно, гештальт-технологии; 3) по форме организации: индивидуальное обучение, коллективное, клубное, альтернативное; 4) по типу управления познавательной деятельностью: обучение по книге, по компьютеру, обучение в малой группе, репетиторство;5) по подходу к ребёнку: личностно-ориентированное, гуманно-личностное, авторитарное, свободного воспитания, технология сотрудничества; 6) по разнообразным категориям обучения: массовая образовательная деятельность, компенсирующий вид обучения, работа с одарёнными детьми, работа с трудными детьми. Образовательный стандарт дошкольного образования предлагает целый арсенал педагогических технологий: это технология развивающего обучения, игровые технологии, технология педагогического сотрудничества, здоровьесберегающие технологии, технологии проблемного обучения, технологии проектной деятельности и др. Эти современные российские инновационные технологии ещё предстоит внедрять в Китае в систему дошкольного образования.

\section{Зак^ючение}

В последние годы укрепились дружественные связи между Россией и Китаем во всех сферах жизни, в том числе и в области образования в сфере подготовки педагогических кадров, как для подготовки учителей средней школы, так и воспитателей дошкольного образования. Совместное сотрудничество двух стран и взаимное участие, путем международного обмена получают глу-

4 ФГОС дошкольного образования. Приказ Министерства Образования и Науки Российской Федерации от 17 октября 2013г. №1 155. г. Москва. «Об утверждении Федерального государственного образовательного стандарта дошкольного образования» 
бокий опыт и практические навыки работы с детьми, что в конечном итоге отражается на воспитании и обучении подрастающего поколения, стирает границы между государствами. Опыт такой работы доказывает, что международная интеграция в педагогической сфере, необходима не только для самих детей, но и для их родителей, педагогов, так как дальнейшая жизнь учащихся напрямую зависит от их качественной подготовки к взрослой жизни, способности к логическому мышлению, овладению в будущем выбранными профессиями, и свободной адаптации в обществе.

Таким образом, рассмотренные исторические аспекты дошкольного образования в Китае и России, а также сравнительные характеристики, имеют большое познавательное и научно-практическое значение, для по- нимания общности и различий в подходах и методах воспитания подрастающего поколения обеих стран. Перспективное сотрудничество между двумя крупнейшими государствами в образовательной сфере дает ощутимые практические результаты, не только в области подготовки педагогических кадров, но и в укреплении дружбы и добрососедства, что имеет важнейшее как экономическое, так и политическое значение.

На протяжении новейшей педагогической истории Китая в области дошкольного образования, под руководством правительства и при участии педагогического сообщества были достигнуты большие успехи, а возникающие проблемы совместно с Россией решаются на высоконаучном уровне.

\section{ЛИТЕРАТУРА}

1. Астапова, В.А. История дошкольного образования в России / В.А. Астапова, Т.Н. Воробьева, Н.М. Чебиняева. - Текст: непосредственный // Молодой ученый. - 2019. - № 52 (290). ᄀ- C. 248-250. - URL: https://moluch.ru/archive/290/65717/ (дата обращения: 04.08.2020).

2. Белая К.Ю. «Организация методической работы с педагогами на этапе введения федерального государственного образовательного стандарта дошкольного образования», Справочник старшего воспитателя, М.: ТЦ Сфера. - 2014. - № 3. - С. 4-13.

3. Белоусова С.С. Современное дошкольное образование в Китайской Народной Республике // Новый подход в развитии инноваций в России : сборник матлов междунар. науч.-практ. конф. (г. Краснодар, 27 января 2018 г.). - Иркутск : Научное партнерство «Апекс», 2018. - С. 36-38.

4. Ван Чуньянь. Историческое просвещение столетия реформы школьной программы дошкольного образования в Китае. - Пекин: Изд-во Пекинского педагогического университета, 2003. - (часть 2). - С. 10.

5. Дошкольное образование в КНР [Электронный ресурс] // URL: https://laowai.ru/doshkolnoe-obrazovanie-v-knr/ (дата 0бращения: 05.08.2020).

6. Мен Щанчин. Образование древнего Китая. - Пекин: Изд-во народного образования, - 1985. - С. 75.

7. Цй. «Ли цзи». - Пекин: Народное педагогическое издательство, - 1990.- С. 25.

8. Чен Сесин. Образование современного Китая. - Пекин: Изд-во народного образования, - 2001. - С. 223.

9. Чжан Лисин. Очерк истории дошкольного образования в Китае [Электронный ресурс] // Преподаватель XXI век. - 2010. - № 4. - Режим доступа: http:// cyber1eninka.ru/artic1e/n/ocherk-istorii-doshko1nogo-obrazovaniya-v-kitae (дата обращения: 6.08.2020).

10. Чжу Ципи. Состояние и тенденции дошкольного образования в России, - Пекин: Изд-во народного образования, - 2001. - С. 5.

11. Ядешко, В.И., Сохина, Ф.А., Ильина, Т.А., Дошкольная педагогика, М.: Просвещение, - 1986. - С. 413. 